\title{
Process re-engineering - commitment, consultants and all that stuff!
}

\author{
C.L. Wood, S.J. Childe \\ Manufacturing and Business Systems, University of Plymouth \\ Drake Circus, Plymouth, PL4 8AA, UK. Tel: 44-1752-232546 \\ Fax:44-1752-233505EMail: cwood@soc.plym.ac.uk
}

\begin{abstract}
This paper presents a re-engineering project undertaken on one company's design and development process. The experiences gained regarding process analysis, management commitment, value chains and consultants are discussed. The lessons learnt are then discussed in the context of a current re-engineering.
\end{abstract}

\section{Keywords}

Consultants, management commitment, process analysis, re-engineering, value chain

\section{INTRODUCTION}

This paper presents the case of a re-engineering project undertaken by a company, in order to make radical improvements within its product design and development process. The success of the project was in itself limited, but the experiences gained can serve as lessons to others undertaking re-engineering projects.

The approach adopted by the company was in line with the radical approach advocated by Hammer and Champy (1993) and Hall et al (1993), therefore no analysis was conducted of the existing processes. This lack of analysis made it difficult for the team to sell the change to the executives, therefore commitment was in some cases tentative. The consultants were released prior to implementation, which left the re-engineering team struggling to put their theoretical process into practice. The team also developed a value chain for the company, but this was met with suspicion from those outside of design and 
development. The paper discusses each of these issues, with regard to their effect on the re-engineering project.

To conclude the paper a current re-engineering project is outlined to illustrate the way in which the company has incorporated the experiences gained from the previous re-engineering project.

\section{THE EXISTING DESIGN AND DEVELOPMENT ACTIVITIES}

The case company designs, develops and manufactures a varied range of products, generally in low volumes. Considered in terms of the categories offered by Wortmann (1989); engineer to order, make to order, assemble to order and make to stock, the company has products within each category. Many of the products are innovative and are designed to meet identified market requirements either independently or in conjunction with a customer. Such engineer to order products are important to the company and therefore design and development was considered to be a key activity.

Restructuring within the company over the previous years had resulted in the formation of project teams for design and development, yet no discernible process had emerged. Each team adopted their own individual approach when designing and developing a product, in isolation from each other and from the rest of the company. The company was organised functionally at that time and interfaces between design and development and other areas such as manufacturing and purchasing were minimal.

According to Pandya et al (1997) and Maull et al (1995), interfaces between product development and order fulfilment are required in order for the company to fulfil the customer's requirements. They believe that the product development process should take the requirements of the customer or market and transform them into a product specification that can be used by the order fulfilment process.

The lack of such interfaces within the case company meant that problems often appeared after design and development had handed the product over to manufacturing. In order to meet customer requirements, these problems had to be resolved which at that stage was generally expensive and time-consuming.

The company realised that this was affecting the performance of the company as a whole, so a re-engineering programme was initiated.

\section{THE RE-ENGINEERING PROJECT}

\section{Project profile}

The re-engineering project was afforded a high profile within the company and its objective was ambitious; to halve the lead time and cost of product development. To achieve such ambitious targets a radical approach was adopted by the team, however their influence was limited solely to design and development. 
The project lasted for almost two years and resulted in the generation of a new design and development process. The results of the project were not as radical as first hoped for, but the experience gained by the company was undoubtedly valuable. These experiences are outlined in the remainder of this paper.

\section{Should the existing design and development activities be analysed?}

Before commencing the re-engineering programme in earnest, the re-engineering team had to convince the executives that there was a real need for change and that the resources required were justified.

The re-engineering team were aware of this, yet since they intended to undertake radical change and design the new process from scratch, they did not analyse any of the existing design and development activities in detail. As a consequence when required to put their case to the executives they had little empirical evidence to support it, rather it was based on instinct and hearsay. The team were able to discuss general weaknesses in the existing design and development method, but could neither prove that they were significant nor offer any indication of the cost of such weaknesses to the company.

It was extremely difficult to convince the executives of the need for change and thus secure their commitment on the basis of what appeared to be a rather superficial case. Eventually the team were given the go ahead to continue with the re-engineering project, though some executives still held reservations regarding the changes.

The radical approach to re-engineering adopted by the case company, is advocated in the work of Hammer and Champy (1993) and Hall et al (1993). These authors believe that radical levels of improvement are achieved through creativity and suggest that an organisation should redesign processes from an 'empty building shell' (Hammer and Champy 1993) or 'clean slate' (Hall et al 1993).

However, the case suggests that it is beneficial to analyse existing activities even in circumstances where radical change is to be undertaken. This analysis should at least examine the performance of the existing system to establish a baseline for improvements. The results of this initial analysis can then be used to illustrate the reasons and need for change to the company.

\section{When should the consultants leave?}

Consultants were brought into the company during the initial stages of the programme to offer guidance to the re-engineering team. They worked with the team in identifying the key areas requiring change, deciding upon an appropriate course of action and presenting the team's recommendations to the executive. The consultants also played a major role in generating the new design and development process.

It was at this stage, once the outline of the new design and development process was known, that the company let the consultants leave. In doing so they left the re- 
engineering team to undertake testing and implementation of the changes unaided. Implementation had not been considered until this point and progress slowed as the re-engineering team struggled to put the new process into practice.

Their difficulties were exacerbated by the fact that the company was becoming impatient, expecting to see results from such a high profile team. This led to a hostile environment, in which implementing change was all the more difficult. The project was behind schedule and the executives were also showing concern regarding the re-engineering programme. It was decided to implement only some of the planned changes and the programme was cut short. Those changes that were implemented have been successful.

The use of consultants to guide companies through re-engineering projects is widespread, but at what point should they leave and the company to take sole responsibility for the change? In this case it would appear that the company were ill prepared for handling the implementation of such a major change project, assuming wrongly that implementation would be straightforward. The guidance of consultants may have been removed just as it was needed the most.

\section{The Value Chain}

According to Porter (1985) a value chain can be used to map internal processes and functions within companies and the relative position of each in the value adding process.

It was in this context that the re-engineering team produced a process map and value chain for the case company. This enabled them to see the role and interactions of the design and development process within the company as a whole. It was the first time that the company had been considered in terms of integrated processes rather than distinct functions.

It became obvious to the re-engineering team that the new design and development process should interface with other processes within the value chain. The concept of a process-based organisation implied by this made some managers nervous, and believing that the re-engineering team were intruding into their territory, they kept them at a distance. This was especially true where they still held reservations about the change. This resistance slowed progress of the reengineering team further.

The re-engineering team were also working within constraints that allowed them to make changes only to design and development, therefore the extent to which they could implement their ideas was limited. The value chain did however provide them with a structure, around which they built the design and development process. Consequently the process that emerged from the re-engineering project considers design and development as an integral process within a value chain, complete with the necessary links to other parts of the company.

It is unfortunate that the concept of a process based organisation and value chain, as introduced by the re-engineering team, were not accepted by the company at that time. This was primarily due to the fact that the re-engineering, though radical, had 
only limited scope and such concepts were alien to a majority of the company. Had the scope of the re-engineering been more widespread, greater improvements may well have been made. The concept of a process-based organisation has now been adopted throughout the company, which has since been reorganised around processes.

\section{THE NEW DESIGN AND DEVELOPMENT PROCESS}

The design and development process that emerged from the re-engineering divides the process into stages, starting with the initial marketing and technological investigation through to the ramping up of production, with checkpoints between each stage.

Each stage consists of generic activities, common to all projects, as well as project-specific activities. All activities in a stage must be completed and judged to have been successful before the next stage can start. If a project fails to satisfy all the criteria sufficiently the project cannot enter the next stage or in extreme cases can be stopped altogether. This ensures that key aspects of design, such as manufacturing feasibility are considered at the early stages of a project.

Design and development projects are run by multidisciplined teams consisting of core members and part time members. The part time members represent those processes that interface with design and development. They maintain communication with the core team throughout the project and are pulled into that team as required. This teamwork promotes communication between processes, ensuring that each is aware of the others' demands and capabilities. As a result potential problems are identified at an early stage when they can be resolved relatively easily, with the minimum of time and money.

\section{LEARNING FROM EXPERIENCE}

It has now been acknowledged by the case company that the re-engineering project within design and development had only limited success. The lessons learnt from undertaking the project however are valuable. Consequently they are currently undertaking a re-engineering project of the whole company, with a somewhat modified approach.

The current re-engineering project combines the radical approach of Hammer and Champy (1993) with the incremental approach of Harrington (1991). Detailed analysis of the existing processes has uncovered some fundamental weaknesses within the organisation and supported by detailed process maps, problem reports and relevant figures these can be highlighted to all in the organisation. The new processes and value chains for the company are been designed using the 'clean slate' of Hall et al (1993) whilst addressing these fundamental issues.

The current re-engineering project is taking a wholistic view of the company, which is likely to be organised around processes and value chains in the future. 
This is possible as the concept of a process-based organisation has now been promoted throughout the company, and each process appreciates the part they play within it.

Finally, when exactly should the consultants leave? The company have learnt that implementation is hard and therefore not only are they addressing it early in the re-engineering, but the consultants are staying to help. They will remain, in a supportive role until the project delivers results.

\section{CONCLUSION}

This paper outlined the experience gained by one company whilst re-engineering their design and development activities. The experience highlights several factors that, if considered before undertaking a re-engineering project, may contribute to its success.

Analysis of existing processes should not be dismissed because radical improvements are sought. Some initial analysis will provide evidence to support and promote the change within the organisation and will enable baseline performance to be assessed.

Careful consideration should be given as to the scope of the re-engineering project. Any changes proposed may affect areas of the company beyond that scope. This is especially true where the re-engineering activities suggest moving from a functional to process-based orientation. The whole company, not just the area being re-engineered must be prepared for the change, otherwise success may be limited.

If a company employs consultants during re-engineering they should be willing and able to retain them until they are confident to continue alone. This may involve a period where consultants are available to offer guidance, but are no longer taking an active role in the re-engineering.

Finally, whether the re-engineering project is a success or a failure the company should learn from the experience and apply that knowledge to future projects.

\section{REFERENCES}

Hall, E.A. Rosenthal, J. and Wade, J. (1993) How to make re-engineering really work. Harvard Business Review. November/December.

Hammer, M. and Champy, J. (1993) Re-engineering the corporation. HarperCollins, New York.

Harrington, J. (1991) Business Process Improvement. McGraw-Hill, New York.

Maull, R. Childe, S. Bennett, J. Weaver, A. and Smart, P. (1995) Different types of manufacturing processes and IDEFo models describing standard business processes. Working paper WP/GR/J95010-6, University of Plymouth.

Pandya, K.V. Karlsson, A. Sega, S. and Carrie, A. (1997) Towards the 
manufacturing enterprises of the future. International journal of operations and production management. 17(5), 502-21.

Porter, M.E. (1985) Competitive Advantage: Creating and sustaining superior performance. The Free Press, New York.

Wortmann, J.C. (1989) Towards an integrated theory for the design, production and production management of complex, one of a kind products in the factory of the future. Proceedings of the 6th annual Esprit conference. Commission of the European Communities, 1089-99.

\section{BIOGRAPHY}

Cita Wood is a research student in the Manufacturing and Business Systems (MABS) research group at the University of Plymouth. She is currently working on the EPSRC grant 'A methodology for the re-engineering of business processes.'

Dr Steve Childe is a joint leader (with Dr Roger Maull) of the Manufacturing and Business Systems (MABS) research group at the University of Plymouth. His research interests include production management and manufacturing systems, business systems, intervention methodologies, implementation and human aspects. $\mathrm{He}$ has held various research grants including currently 'A methodology for the reengineering of business processes.' $\mathrm{He}$ is the author of An Introduction to Computer Aided Production Management and a member of IFIP's Working Group 5.7 on computer aided production management. 